\title{
The impact of HCV co-infection status on healthcare-related utilization among people living with HIV in British Columbia, Canada: a retrospective cohort study
}

Huiting Ma ${ }^{1}$, Conrado Franco Villalobos², Martin St-Jean², Oghenowede Eyawo², Miriam Ruth Lavergne ${ }^{3}$, Lianping $\mathrm{Ti}^{2}$, Mark W. Hull${ }^{4}$, Benita Yip², Lang Wư ${ }^{5}$, Robert S. Hogg ${ }^{2}$, Rolando Barrios², Jean A. Shoveller ${ }^{6}$, Julio S. G. Montaner ${ }^{4}$ and Viviane D. Lima ${ }^{2^{*}}$ (D)

\begin{abstract}
Background: The burden of HCV among those living with HIV remains a major public health challenge. We aimed to characterize trends in healthcare-related visits (HRV) of people living with HIV (PLW-HIV) and those living with HIV and HCV (PLW-HIV/HCV), in British Columbia (BC), and to identify risk factors associated with the highest HRV rates over time.

Methods: Eligible individuals, recruited from the BC Seek and Treat for Optimal Prevention of HIV/AIDS population-based retrospective cohort $(N=3955)$, were $\geq 18$ years old, first started combination antiretroviral therapy (ART) between 01/01/ 2000-31/12/2013, and were followed for $\geq 6$ months until 31/12/2014. The main outcome was HRV rate. The main exposure was HIV/HCV co-infection status. We built a confounder non-linear mixed effects model, adjusting for several demographic and time-dependent factors.
\end{abstract}

Results: HRV rates have decreased since 2000 in both groups. The overall age-sex standardized HRV rate (per person-year) among PLW-HIV and PLW-HIV/HCV was 21.11 (95\% Cl 20.96-21.25) and 41.69 (95\% Cl 41.51-41.88), respectively. The excess in HRV in the co-infected group was associated with late presentation for ART, history of injection drug use, suboptimal ART adherence and a higher number of comorbidities. The adjusted HRV rate ratio for PLW-HIV/HCV in comparison to PLW-HIV was 1.18 (95\% Cl 1.13-1.24).

Conclusions: Although HRV rates have decreased over time in both groups, PLW-HIV/HCV had 18\% higher HRV than those only living with HIV. Our results highlight several modifiable risk factors that could be targeted as potential means to minimize the disease burden of this population and of the healthcare system.

Keywords: HIV, Hepatitis C virus, Healthcare utilization, Administrative data, Risk factors

\section{Background}

In high-income settings, HIV infection has become a chronic manageable condition [1]. Overall, HIV/AIDS associated morbidity and mortality has decreased to unprecedented levels, largely due to the widespread use of combination antiretroviral therapy (ART) [2]. People living with HIV/AIDS (PLW-HIV) now have life expectancies comparable to those observed in the general

\footnotetext{
*Correspondence: vlima@cfenet.ubc.ca

${ }^{2}$ British Columbia Centre for Excellence in HIV/AIDS, 608 - 1081 Burrard

Street, Vancouver, BC V6Z 1Y6, Canada

Full list of author information is available at the end of the article
}

population, although variability between sub-groups remain [3]. Despite successful treatment-mediated viral suppression, premature morbidity and mortality due to non-AIDS related infectious and non-infectious comorbidities are increasingly prevalent, raising new challenges for healthcare providers and health systems [4].

Globally, the hepatitis $\mathrm{C}$ virus (HCV) has become one of the most prevalent co-infection among PLW-HIV [5]. Indeed, HCV mortality has surpassed that of all other reportable infectious diseases together, including AIDS and tuberculosis, in the United States [6]. According to a recent meta-analysis, the prevalence of both HIV and

(c) The Author(s). 2018 Open Access This article is distributed under the terms of the Creative Commons Attribution 4.0 International License (http://creativecommons.org/licenses/by/4.0/), which permits unrestricted use, distribution, and reproduction in any medium, provided you give appropriate credit to the original author(s) and the source, provide a link to the Creative Commons license, and indicate if changes were made. The Creative Commons Public Domain Dedication waiver (http://creativecommons.org/publicdomain/zero/1.0/) applies to the data made available in this article, unless otherwise stated. 
$\mathrm{HCV}$ is the highest (82\%) among people who inject drugs (PWID) [5]. In Canada, similar to the United States, $20 \%$ to $30 \%$ of PLW-HIV are also living with $\mathrm{HCV}$, while the prevalence of both viruses among PWID ranges between 50\% and 90\% [7-9]. In addition, the presence of both viruses has been shown to increase the risk for clinical progression of HIV as well as premature mortality (despite ART), and accelerated progression of HCV-associated liver diseases $[10,11]$.

Enhanced immunosenescence, resulting from HIV infection via persistent inflammatory activity and immune activation, is associated with increased morbidity and mortality $[12,13]$. It is becoming increasingly evident that $\mathrm{HCV}$ infection also contributes to systemic immunosenescence [14-16]. Of note, HCV-related disease burden is not restricted to the liver; it extends to several conditions (immune-mediated or activated by chronic inflammation) impacting extrahepatic organs/tissues [17]. Additionally, life-style factors, socio-economic constraints, and inadequate engagement in care tend to exacerbate other comorbid conditions, further complicating clinical outcomes among some subgroups of PLW-HIV, particularly those co-infected with $\operatorname{HCV}[18,19]$.

To date, a large number of people living with HIV and $\mathrm{HCV}$ (PLW-HIV/HCV) have no or limited access to $\mathrm{HCV}$ treatment. However, very recently, the healthcare landscape in British Columbia (BC), Canada, has been rapidly transforming with the advent of highly efficacious and tolerated $\mathrm{HCV}$ direct-acting antiviral therapies, resulting in a steady increase in the number of individuals accessing this life-saving therapy [20, 21]. Still, there are barriers for accessing healthcare services and programs for those afflicted by these diseases that need to be identified, particularly among those who are marginalized and vulnerable in the population [20].

Thus, the main objective of this study was to characterize the trends in healthcare-related visits (HRV) of PLW-HIV and PLW-HIV/HCV, in BC. Additionally, we aimed at identifying modifiable risk factors, associated with the highest HRV rates over time that could be targeted as potential means to minimize the disease burden of this population and on the healthcare system.

\section{Methods}

\section{Study setting}

The province of $\mathrm{BC}$ established the $\mathrm{BC}$ Centre for Excellence in HIV/AIDS Drug Treatment Program (DTP) in 1992; it has since been responsible for the distribution of antiretrovirals [22]. The DTP, funded by the provincial government, provides HIV medical care and laboratory monitoring (e.g., CD4 cell counts and viral load) for all diagnosed PLWH residing in $\mathrm{BC}$ at no cost, in accordance with BC's HIV therapeutic guidelines, which have largely remained consistent with those of the International Antiviral Society-USA since 1996 [23, 24].

\section{Study design and data}

This retrospective study was carried out using data from the British Columbia Seek and Treat for Optimal Prevention of HIV/AIDS (STOP HIV/AIDS) populationbased cohort, which is derived from various linkages among provincial databases [22, 25-30]. This cohort is briefly described in the Additional file 1 . Our inclusion criteria for individuals were as follows: (i) ART-naive individuals aged $\geq 18$ years, (ii) enrolled in the (DTP) between January 1, 2000 and December 31, 2013, (iii) initiated ART consisting of two nucleoside/nucleotide reverse transcriptase inhibitors (NRTIs) as backbone, plus either a non-nucleoside reverse transcriptase inhibitor (NNRTI) or a ritonavir-boosted protease inhibitor (bPI), (iv) had a CD4 count and a viral load measurement within 6 months of ART treatment initiation, and (v) had at least 6 months of follow-up. Note that we decided to exclude other initial ART regimens due to the small number of individuals who have initiated on them. Eligible individuals were followed until December 31, 2014, the last contact date (i.e., the last available laboratory test date, the last filled ART prescription refill date or the date of last encounter with the healthcare system identified in any of the STOP HIV/AIDS databases), or the date of death (all-causes).

All viral load tests and the majority of CD4 cell count tests were performed by the St. Paul's Hospital laboratories in Vancouver, BC, and were subsequently transferred to the DTP via electronic linkage. CD4 cell count tests completed at other laboratories throughout BC were manually entered into the DTP; altogether resulting in approximately $85 \%$ data capture of all CD4 cell count tests done in the province. For analytical purposes, all viral load measurements were transformed to range from $<50$ (coded as 49) to $>100,000$ (coded as 100,010) copies/mL. This process was necessary to account for advances in testing methodology, as previously described elsewhere [31]. CD4 cell counts were measured by flow cytometry (Beckman Coulter, Inc., Mississauga, Ontario).

\section{Main outcome}

The main outcome was the rate of HRV per individual for every 6-month interval. HRV was calculated based on records from the Medical Services Plan (MSP) billing provincial database linked to STOP HIV/AIDS cohort. MSP captures HIV and non-HIV-related inpatient and outpatient services provided by physicians and supplementary health care practitioners, as well as diagnostic procedures. The unit of analysis for the crude HRV rate was personyear, which was calculated by dividing the number of HRV by the number of person-years of follow-up in each 
calendar year. The corresponding 95\% confidence intervals (CI) for these rates were based on the Fisher's exact test [32]. Note that we also presented the age-sex standardized HRV rates for the overall follow-up utilizing BC's population estimates as the reference [33].

The number of HRV was derived from the MSP physician billing records, which contain the date, type and location of service, physician number, practitioner speciality and costs. Since multiple MSP database records could be associated with one unique HRV, a record was considered to be a unique HRV if it satisfied one of the following conditions:

i. If the service date, which is the date on which the service was rendered by a practitioner, was different; or

ii. If the speciality number, which is a number assigned to identify the practitioner's specialty, was different; or

iii. If the location of the service was different.

Once the rules outlined above were adopted, we identified the unique HRV for these individuals. Subsequently, we calculated the number of HRV in each 6month interval for all individuals. Visits were classified as general practitioners, other healthcare practitioners, and laboratory services.

\section{Main exposure variable}

The main exposure variable of interest was $\mathrm{HIV} / \mathrm{HCV}$ co-infection status, derived from the DTP database, which indicates whether PLW-HIV has ever had evidence of $\mathrm{HCV}$ infection (i.e., a HCV antibody positive or $\mathrm{HCV}$ RNA detected, as indicated by laboratory result data or physician reported status). Note that upon successful HCV treatment, individuals can become reinfected with HCV. Thus, we were only able to incorporate $\mathrm{HCV}$ ever status for these individuals.

\section{Potential confounders}

The confounders measured at ART initiation included: sex (male, female), risk for HIV acquisition (gay, bisexual and other men who have sex with men (MSM), PWID, MSM/PWID, Other, Unknown), initial ART regimen (NNRTI, bPI) and period of ART initiation (2000-2003, 2004-2007, 2008-2011, 2012-2013). Several timevarying confounders, measured every year, were considered in this study, including: age $(<30,30-39,40-49$, $\geq 50$ years), CD4 cell count $(<50,50-199,200-349, \geq 350$ cells $/ \mathrm{mm}^{3}$ ), viral load ( $\log _{10}$ transformed), adherence level (<40\%, 40-79\%, 80-94\%, $\geq 95 \%)$, cumulative number of comorbid diseases $(0,1,2, \geq 3)$ and personyears of follow-up time. Adherence level was determined on the basis of a validated measure assessing refill compliance, which was calculated by dividing the amount of days of dispensed ART medication by the amount of days of study follow-up, for each period (presented as percentage). ART adherence calculations were derived from distinct regimen exposures for each individual [34]. PWID included individuals with past and current exposure to injection drug use. Individual comorbidities were derived from the Charlson Comorbidity Index (Additional file 1: Table S1) [35]. These included 16 conditions, other than HIV/AIDS (e.g., renal, liver, heart and lung diseases and cancer). These conditions were identified using International Classification of Diseases (Ninth and Tenth Revisions, Clinical Modification) diagnosis codes obtained from the STOP HIV/AIDS cohort databases based on a validated casefinding algorithm [36].

\section{Statistical analysis}

Categorical variables were compared using the Fisher's exact test or the $X^{2}$ test, and continuous variables were compared using the Kruskal-Wallis test [37]. Based on exploratory data analyses to determine the best distribution for modeling HRV rates, non-linear mixed effects models were used assuming a Poisson distribution, the person-years of follow-up time as the offset, a log link function, a random intercept term and an autoregressive of order one working correlation matrix [38]. We have chosen these models since they are flexible in taking into account the inter- and intra-individual sources of variation, they can handle imbalanced longitudinal data, and zero-inflated models did not show any gain over the final fitted model [38, 39]. Potential confounders were selected for inclusion in the final model using a backward-selection approach, published by our group based on the work by Maldonado and Greenland [40], that considered the magnitude of change in the coefficient of the HIV/HCV co-infection status variable. Specifically, starting with a fixed model, which considered all available variables, potential confounders were dropped one at a time, using the relative change in the coefficient for the variable related to the $\mathrm{HIV} / \mathrm{HCV}$ coinfection status as a criterion, until the maximum change from the full model exceeded 5\% [41]. Note that in the multivariable model, we did not adjust for risk for HIV acquisition given its high collinearity with the main study exposure. All analyses were performed using either $\mathrm{R} \odot$ version 3.3.2 (The $\mathrm{R}$ foundation for statistical computing, Vienna, Austria) or SAS version 9.4 (SAS, Cary, North Carolina, USA).

\section{Results}

Cohort characteristics

Overall, 4217 ART-naïve adults with a total of 615,776

HRV were initially eligible to participate in this study. 
Table 1 Study population characteristics by inclusion status

\begin{tabular}{|c|c|c|c|c|}
\hline \multirow[t]{2}{*}{ Variables } & \multirow{2}{*}{$\begin{array}{l}\text { Overall } \\
N=4217\end{array}$} & \multirow{2}{*}{$\begin{array}{l}\text { Included } \\
N=3955\end{array}$} & \multirow{2}{*}{$\begin{array}{l}\text { Excluded } \\
N=262\end{array}$} & \multirow[t]{2}{*}{$P$-value } \\
\hline & & & & \\
\hline \multicolumn{5}{|l|}{ Sex, n(\%) } \\
\hline Female & $805(19)$ & $735(91)$ & $70(9)$ & \multirow[t]{2}{*}{0.0016} \\
\hline Male & $3412(81)$ & $3220(94)$ & $192(6)$ & \\
\hline \multicolumn{5}{|l|}{ Status } \\
\hline HIV mono-infected & $2333(55)$ & $2333(100)$ & $0(0)$ & \multirow[t]{3}{*}{ NA } \\
\hline HIV/HCV co-infected & $1622(39)$ & $1622(100)$ & $0(0)$ & \\
\hline Unknown & $262(6)$ & $0(0)$ & $262(100)$ & \\
\hline \multicolumn{5}{|c|}{ Age at ART initiation (years), n (\%) } \\
\hline$<30$ & $516(12)$ & $481(93)$ & $35(7)$ & \multirow[t]{4}{*}{0.1724} \\
\hline $30-39$ & $1294(31)$ & $1216(94)$ & $78(6)$ & \\
\hline $40-49$ & $1523(36)$ & $1441(95)$ & $82(5)$ & \\
\hline$\geq 50$ & $884(21)$ & $817(92)$ & $67(8)$ & \\
\hline \multicolumn{5}{|l|}{ Risk, n(\%) } \\
\hline MSM & $1376(33)$ & $1294(94)$ & $82(6)$ & \multirow[t]{5}{*}{$<0.0001$} \\
\hline PWID & $1335(32)$ & $1298(97)$ & $37(3)$ & \\
\hline MSM/ PWID & $314(7)$ & $309(98)$ & $5(2)$ & \\
\hline Other & $652(15)$ & $581(89)$ & $71(11)$ & \\
\hline Unknown & $540(13)$ & $473(88)$ & $67(12)$ & \\
\hline \multicolumn{5}{|l|}{ ART era, n(\%) } \\
\hline 2000-2003 & $859(20)$ & 797 (93) & $62(7)$ & \multirow[t]{4}{*}{0.1037} \\
\hline 2004-2007 & $1214(29)$ & $1153(95)$ & $61(5)$ & \\
\hline 2008-2011 & $1704(40)$ & $1599(94)$ & $105(6)$ & \\
\hline 2012-2013 & $440(10)$ & $406(92)$ & $34(8)$ & \\
\hline \multicolumn{5}{|l|}{$\begin{array}{l}\text { Baseline CD4 cell count } \\
(\text { cells/mm³), n (\%) }\end{array}$} \\
\hline$<50$ & $498(12)$ & $474(95)$ & $24(5)$ & \multirow[t]{4}{*}{0.4136} \\
\hline 50-199 & $1366(32)$ & $1285(94)$ & $81(6)$ & \\
\hline $200-349$ & $1329(32)$ & $1238(93)$ & $91(7)$ & \\
\hline$\geq 350$ & $1024(24)$ & $958(94)$ & $66(6)$ & \\
\hline \multicolumn{5}{|l|}{$\begin{array}{l}\text { ART Adherence (first six } \\
\text { months), } \mathrm{n}(\%)\end{array}$} \\
\hline$\geq 95 \%$ & $3291(78)$ & $3084(94)$ & $207(6)$ & \multirow[t]{4}{*}{0.7563} \\
\hline $80-94 \%$ & $218(5)$ & $208(95)$ & $10(5)$ & \\
\hline $40-79 \%$ & $474(11)$ & $445(94)$ & $29(6)$ & \\
\hline$<40 \%$ & $234(6)$ & $218(93)$ & $16(7)$ & \\
\hline \multicolumn{5}{|l|}{$\begin{array}{l}\text { Number of comorbidities } \\
\text { at baseline, } n(\%)\end{array}$} \\
\hline 0 & $1451(34)$ & $1357(94)$ & $94(6)$ & \multirow[t]{4}{*}{0.8122} \\
\hline 1 & $1397(33)$ & 1307 (94) & $90(6)$ & \\
\hline 2 & $768(18)$ & $725(94)$ & $43(6)$ & \\
\hline$\geq 3$ & $601(14)$ & $566(94)$ & $35(6)$ & \\
\hline \multicolumn{5}{|l|}{ Initial ART regimen, $\mathrm{n}(\%)$} \\
\hline NNRTI & 2033 (48) & 1895 (93) & $138(7)$ & 0.1531 \\
\hline
\end{tabular}


Table 1 Study population characteristics by inclusion status (Continued)

\begin{tabular}{llll}
\hline Variables & Overall & Included & Excluded \\
$N=4217$ & $N=3955$ & N=262 \\
\hline \multicolumn{1}{c}{ bPI } & $2184(52)$ & $2060(94)$ & $124(6)$ \\
$\begin{array}{l}\text { Total healthcare-related visits, } \\
\text { median (Q1-Q3) }\end{array}$ & $97(48-187)$ & $99(49-191)$ & $71(31-125)$ \\
$\begin{array}{l}\text { Baseline viral load (log } 10 \text { copies/mL), } \\
\text { median (Q1-Q3) }\end{array}$ & $4.90(4.38-5.00)$ & $4.90(4.38-5.00)$ & $4.85(4.28-5.00)$ \\
\begin{tabular}{l} 
Follow-up time (years), median (Q1-Q3) \\
\hline
\end{tabular} & $4.99(2.50-7.98)$ & $4.99(2.81-8.00)$ & $3.50(1.76-5.99)$
\end{tabular}

Q1-Q3: 25th - 75th percentiles; MSM: Gay, bisexual and other men who have sex with men; PWID: people who have ever injected drugs; ART: combination antiretroviral therapy; NNRTI: non-nucleoside reverse transcriptase inhibitor; bPI: ritonavir-boosted protease inhibitor; NA: not applicable. Note that Overall column shows column percent, while Included/Excluded columns show row percent

Among these individuals, $81 \%$ were males, $67 \%$ were aged between 30 and 49 years, $72 \%$ were either MSM, PWID or both, 40\% started ART between 2008 and 2011, 76\% initiated ART with a CD4 cell count $<350$ cells $/ \mathrm{mm}^{3}$ and had a median viral load $4.90 \log _{10}$ copies/ $\mathrm{mL}$ (25th-75th percentile (Q1-Q3): 4.38-5.00 $\log _{10}$ copies $/ \mathrm{mL}$ ), $52 \%$ started on a bPI-based ART, $78 \%$ had adherence $\geq 95 \%$ during the first six months on ART, and $34 \%$ had no comorbidities while $14 \%$ had 3 or more. The median follow-up time was 4.99 (Q1-Q3: 2.50-7.98) years, in which the median number of HRV was 97 (Q1Q3: 48-187) (Table 1). This cohort comprised of 2333 (55\%) PLW-HIV, 1622 (39\%) PLW-HIV/HCV, and 262 (6\%) whose HCV status was unknown. The distribution of study variables among those included in this analysis $(N=3955)$ was very similar to the original 4217 individuals described above. For the purposes of this study, those with unknown $\mathrm{HCV}$ status, who contributed 25,393 HRV (4\% of total visits), were excluded from the subsequent analyses. As noted in Table 1, those excluded were more likely to have risk for HIV acquisition other than MSM or PWID, a lower number of HRV and a slight shorter follow-up time.

\section{Characteristics by HIV/HCV co-infection status}

Bivariable analysis exploring associations between study characteristics and HCV co-infection status (shown in Table 2) revealed that PLW-HIV and PLW-HIV/HCV differed significantly in all study characteristics, except for initial ART regimen. PLW-HIV/HCV were more likely to be younger, female, PWID, initiate ART prior to 2008, have a lower CD4 cell count and viral load measurement at baseline, and maintain adherence $<40 \%$ during follow-up. Additionally, these individuals were also more likely to present with and develop a higher number of comorbidities compared to PLW-HIV. The number of $\mathrm{PLW}-\mathrm{HIV} / \mathrm{HCV}$ with moderate or severe liver disease increased substantially during follow-up (75 (5\%) to 124 (8\%); $p$-value 0.0004). Apart from liver disease, chronic pulmonary disease and cancer (all causes) were the most prevalent comorbidities (results not shown).

\section{Trends in healthcare-related visits}

The overall age-sex standardized HRV rate for PLWHIV and PLW-HIV/HCV was 21.11 per person-year (95\% CI 20.96-21.25) and 41.69 per person-year $(95 \%$ CI 41.51-41.88), respectively. For PLW-HIV/HCV, visits were mainly related to methadone or buprenorphine/naloxone treatment, and not to the same extent, to laboratory tests done to monitor liver and kidney function and the hematology profile. For PLW-HIV, most visits were concerned with the latter. As demonstrated in Fig. 1a, the annual crude HRV rates in both groups have been steadily decreasing from 2000 to 2013 . The decrease in HRV rates was more prominent for PLW-HIV (34.28 per person-year to 17.98 per person-year; $48 \%$ decrease; $p$-value <0.0001) compared to PLW-HIV/HCV (48.57 per person-year to 33.92 per person-year; $30 \%$ decrease; p-value $<0.0001$ ). The trends in HRV rates stratified by $\mathrm{HIV} / \mathrm{HCV}$ co-infection status and by the type of HRV are illustrated in Fig. 1b. As shown, except for HRV rates related to laboratory services, PLW-HIV/HCV consistently maintained higher rates, especially those related to general practitioner visits ( $>2$ times higher). Note that the rates for other healthcare practitioners (which includes visits to specialists), although much lower than the HRV rates for general practitioner visits, they have been more stable over time and the difference between these groups was not as pronounced. More detailed information on these trends can be found in Additional file 1: Table S2. The result of the multivariable confounder model showed that the adjusted HRV rate ratio for PLWHIV/HCV in comparison to PLW-HIV was 1.18 (95\% CI 1.13-1.24), after controlling for sex, age, ART era, timevarying $C D 4$, adherence to $A R T$, viral load and the number of comorbidities (Table 3).

\section{Discussion}

This population-based cohort study adds to the growing body of evidence indicating that PLW-HIV/HCV incur significantly greater HRV rates relative to those only living with HIV [42-44]. It is worth noting that although PLW$\mathrm{HIV} / \mathrm{HCV}$ experienced an $18 \%$ higher rate relative to 
Table 2 Study population characteristics by hepatitis C ( $\mathrm{HCV}$ ) co-infection status

\begin{tabular}{|c|c|c|c|}
\hline \multirow[t]{2}{*}{ Variables } & HIV mono-infected & HIV/HCV co-infected & \multirow[t]{2}{*}{$P$-value } \\
\hline & $N=2333$ & $N=1622$ & \\
\hline \multicolumn{4}{|l|}{ Sex, n(\%) } \\
\hline Female & $269(37)$ & $466(63)$ & \multirow[t]{2}{*}{$<0.0001$} \\
\hline Male & $2064(64)$ & $1156(36)$ & \\
\hline \multicolumn{4}{|c|}{ Age at ART initiation (years), n(\%) } \\
\hline$<30$ & $304(63)$ & $177(37)$ & \multirow[t]{4}{*}{$<0.0001$} \\
\hline $30-39$ & $726(60)$ & $490(40)$ & \\
\hline $40-49$ & $780(54 \%)$ & $661(46 \%)$ & \\
\hline$\geq 50$ & $523(64 \%)$ & $294(36 \%)$ & \\
\hline \multicolumn{4}{|l|}{ Risk, n(\%) } \\
\hline MSM & $1144(88)$ & $150(12)$ & \multirow[t]{5}{*}{$<0.0001$} \\
\hline IDU & $122(9)$ & $1176(91)$ & \\
\hline MSM/IDU & $122(39)$ & $187(61)$ & \\
\hline Other & $514(88)$ & $67(12)$ & \\
\hline Unknown & $431(91)$ & $42(9)$ & \\
\hline \multicolumn{4}{|l|}{ ART era, n(\%) } \\
\hline $2000-2003$ & $403(51)$ & $394(49)$ & \multirow[t]{4}{*}{$<0.0001$} \\
\hline 2004-2007 & $628(54)$ & $525(46)$ & \\
\hline 2008-2011 & $1001(63)$ & $598(37)$ & \\
\hline $2012-2013$ & $301(74)$ & $105(26)$ & \\
\hline \multicolumn{4}{|c|}{ Baseline CD4 cell count (cells/mm³), n(\%) } \\
\hline$<50$ & $276(58)$ & $198(42)$ & \multirow[t]{4}{*}{$<0.0001$} \\
\hline 50-199 & $640(50)$ & $645(50)$ & \\
\hline 200-349 & $746(60)$ & $492(40)$ & \\
\hline$\geq 350$ & $671(70)$ & $287(30)$ & \\
\hline \multicolumn{4}{|c|}{ Last CD4 cell count (cells/mm³), n(\%) } \\
\hline$<50$ & $40(33)$ & $81(67)$ & \multirow[t]{5}{*}{$<0.0001$} \\
\hline 50-199 & $101(31)$ & $228(69)$ & \\
\hline 200-349 & $232(46)$ & $277(54)$ & \\
\hline$\geq 350$ & $1732(67)$ & $864(33)$ & \\
\hline Unknown & $228(57)$ & $172(43)$ & \\
\hline \multicolumn{4}{|c|}{ ART Adherence (first six months), $\mathrm{n}(\%)$} \\
\hline$\geq 95 \%$ & $1987(64)$ & $1097(36)$ & \multirow[t]{4}{*}{$<0.0001$} \\
\hline $80-94 \%$ & $100(48)$ & $108(52)$ & \\
\hline $40-79 \%$ & $182(41)$ & $263(59)$ & \\
\hline$<40 \%$ & $64(29)$ & $154(71)$ & \\
\hline \multicolumn{4}{|c|}{ ART Adherence (last six months), n(\%) } \\
\hline$\geq 95 \%$ & $1821(65)$ & $960(35)$ & \multirow[t]{4}{*}{$<0.0001$} \\
\hline $80-94 \%$ & $122(47)$ & $140(53)$ & \\
\hline $40-79 \%$ & $224(45)$ & $277(55)$ & \\
\hline$<40 \%$ & $166(40)$ & $245(60)$ & \\
\hline \multicolumn{4}{|c|}{ Number of comorbidities at baseline, $n(\%)$} \\
\hline 0 & $1067(79)$ & $290(21)$ & \multirow[t]{2}{*}{$<0.0001$} \\
\hline 1 & $745(57)$ & $562(43)$ & \\
\hline
\end{tabular}


Table 2 Study population characteristics by hepatitis C (HCV) co-infection status (Continued)

\begin{tabular}{|c|c|c|c|}
\hline \multirow[t]{2}{*}{ Variables } & \multirow{2}{*}{$\begin{array}{l}\text { HIV mono-infected } \\
N=2333\end{array}$} & \multirow{2}{*}{$\begin{array}{l}\text { HIV/HCV co-infected } \\
N=1622\end{array}$} & \multirow[t]{2}{*}{$P$-value } \\
\hline & & & \\
\hline 2 & $331(46)$ & $394(54)$ & \\
\hline$\geq 3$ & $190(34)$ & $376(66)$ & \\
\hline \multicolumn{4}{|l|}{ Number of comorbidities at the end of follow-up, n(\%) } \\
\hline 0 & $961(82)$ & $215(18)$ & \multirow[t]{4}{*}{$<0.0001$} \\
\hline 1 & $687(62)$ & $421(38)$ & \\
\hline 2 & $333(47)$ & $382(53)$ & \\
\hline$\geq 3$ & $352(37)$ & $604(63)$ & \\
\hline \multicolumn{4}{|l|}{ Initial ART regimen, n(\%) } \\
\hline NNRTI & $1098(58)$ & $797(42)$ & \multirow[t]{2}{*}{0.2109} \\
\hline bPI & $1235(60)$ & $825(40)$ & \\
\hline Total healthcare-related visits, median (Q1-Q3) & $83(43-150)$ & $143(68-278)$ & $<0.0001$ \\
\hline Baseline viral load ( $\log _{10}$ copies/mL), median (Q1-Q3) & $4.92(4.42-5.00)$ & $4.87(4.35-5.00)$ & 0.0048 \\
\hline Last viral load (log 10 copies/mL), median (Q1-Q3) & $1.69(1.69-1.69)$ & 1.69 (1.69-1.98) & $<0.0001$ \\
\hline Follow-up time (years), median (Q1-Q3) & $4.95(2.50-7.91)$ & $5.30(2.99-8.31)$ & 0.0038 \\
\hline
\end{tabular}

Q1-Q3: 25th - 75th percentiles; MSM: Gay, bisexual and other men who have sex with men; PWID: people who have ever injected drugs; ART: combination antiretroviral therapy; NNRTI: non-nucleoside reverse transcriptase inhibitor; bPI: ritonavir-boosted protease inhibitor

PLW-HIV, we observed a decrease in HRV rates over time among both groups, even after controlling for several confounders including disease severity and the cohort effect. Apart from $\mathrm{HCV}$ infection, the excess in HRV rates among PLW-HIV/HCV were at least partially attributable to the fact that these individuals had a history of injection drug use, presented later for HIV treatment, had suboptimal adherence to ART and had higher prevalence of comorbidities.

To understand the reason behind the decreasing rates over time, the reader should be aware that the study period encompasses three phases of BC's response to HIV/AIDS: the harm reduction and health service scaleup phase (2000-2005); the early Treatment as Prevention phase (2006-2009); and the STOP HIV/AIDS phase (2010-present), during which BC's HIV therapeutic guidelines recommended ART treatment for all adults with HIV infection, regardless CD4 count [45, 46]. Throughout these phases, various HIV care initiatives have been implemented and may have attenuated the healthcare-related utilization of this population. Namely, the evolving deployment of biomedical and health service interventions (e.g., the development of improved antiretroviral drugs, substance use treatment, and medication adherence support) and structural interventions (e.g., legal and policy), which have been comprehensive described elsewhere [45].

We should also note that both groups of individuals were linked to HIV care and receiving treatment. Most likely, if people only living with $\mathrm{HCV}$ were included in this analysis, we would see that these trends, in this same period, did not decrease given that, in BC, most of these individuals are not fully engaged into care. In addition, given the recent approval for use of safer, more tolerable and efficacious interferon-free direct acting antivirals-based $\mathrm{HCV}$ therapy, going forward, these trends will likely change, particularly for specialistrelated visits as they will be the ones mainly prescribing these medications and following these individuals. Thus, there is a need for continued monitoring and evaluation of HRV among PLW-HIV/HCV, especially since in 2017, the BC Ministry of Health has announced a provincewide expansion of $\mathrm{HCV}$ treatment to all of those living with HCV starting in March 2018 [21].

The persisting disparity in HRV rates observed among PLW-HIV and PLW-HIV/HCV clearly indicates that there is a critical need for interventions that may attenuate the risk of requiring higher resource use for care among those living with both viruses. Additionally, any successful strategy to attenuate the utilization of PLW$\mathrm{HIV} / \mathrm{HCV}$ will require significant levels of treatment uptake and adherence, especially among PWID (including PLW-HIV/HCV). Our data also suggest that addressing the underlying substance use disorder may be beneficial in this regard. Furthermore, doing so would also contribute to preventing HCV reinfection, which would greatly enhance the individual and societal impact of interferonfree direct acting antivirals-based HCV therapy [47-49]. On that note, several clinical models have proved to be successful in this regard by combining services aimed to address viral hepatitis and HIV, substance use detoxification, opioid substitution, and primary care in low 

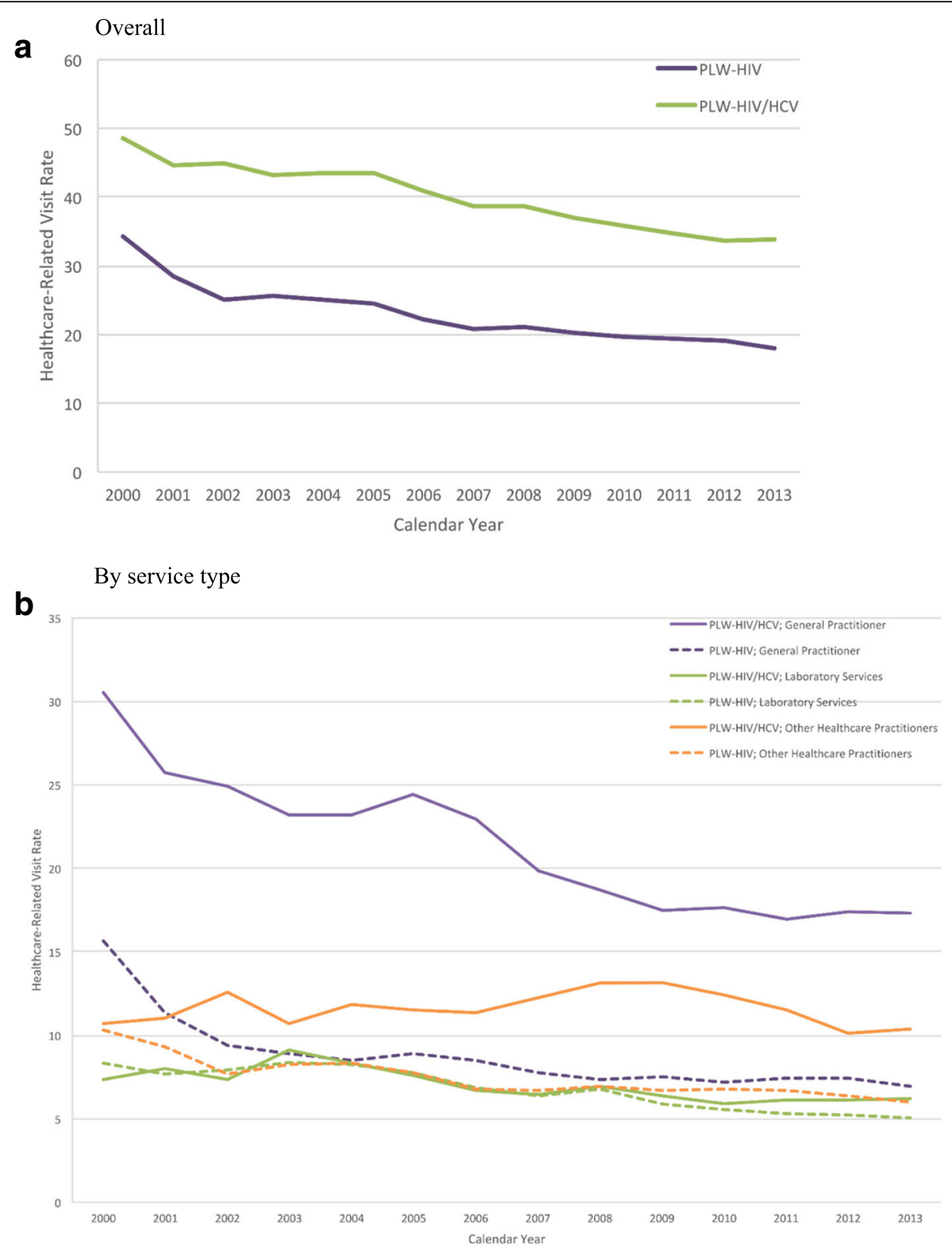

Fig. 1 Crude rate of healthcare-related visits (per person-year) for PLW-HIV and PLW-HIV/HCV, from 2000 to 2013. Panel a, corresponds to the overall healthcare-related visit rate. Panel $\mathbf{b}$ corresponds to the healthcare-related visit rate stratified by service type

threshold environment, coupled with comprehensive and integrated multidisciplinary teams of health care professionals including treaters, nurses, substance use and behavioral health service providers, as well as other social support services [48]. In 2016, the BC Centre for Excellence in HIV/AIDS launched a province-wide monitoring and evaluation strategy, which will address the health needs of those living with or at risk of HCV infection, including those also living with HIV $[50,51]$. The key aims of this program include the normalization of $\mathrm{HCV}$ testing, especially among those at higher risk; support to facilitate access to $\mathrm{HCV}$ and substance use treatment; extensive deployment of harm reduction strategies; and strengthening of educational programs to treat and care for this population.

The implications of $\mathrm{HIV} / \mathrm{HCV}$ co-infection in the context of a rapidly expanding population of aging PLW-HIV are important, particularly at a time when meeting health demands in $\mathrm{BC}$, and in other highresource settings, is becoming exceedingly challenging amid fiscal constraints [52]. As PLW-HIV live longer and non-AIDS-related comorbidities continue to rise, the impact of $\mathrm{HIV} / \mathrm{HCV}$ co-infection will be increasingly relevant, both from a clinical perspective and a 
Table 3 Results from the multivariable confounder model

\begin{tabular}{|c|c|c|}
\hline \multirow[t]{2}{*}{ Variables } & \multicolumn{2}{|c|}{ Rate Ratio (95\% Confidence Interval) } \\
\hline & Unadjusted Model & Adjusted Model \\
\hline \multicolumn{3}{|l|}{ Status } \\
\hline HIV mono-infected & $1(-)$ & $1(-)$ \\
\hline HIV/HCV co-infected & $1.65(1.57-1.73)$ & $1.18(1.13-1.24)$ \\
\hline \multicolumn{3}{|l|}{ Sex } \\
\hline Male & $1(-)$ & $1(-)$ \\
\hline Female & $1.45(1.36-1.54)$ & $1.19(1.13-1.25)$ \\
\hline \multicolumn{3}{|l|}{ Age at ART initiation (years) } \\
\hline$<30$ & $1(-)$ & $1(-)$ \\
\hline $30-39$ & $1.08(1.07-1.10)$ & Not selected \\
\hline $40-49$ & $1.23(1.21-1.25)$ & \\
\hline$\geq 50$ & $1.47(1.43-1.50)$ & \\
\hline \multicolumn{3}{|l|}{ ART era } \\
\hline 2000-2003 & $1(-)$ & $1(-)$ \\
\hline $2004-2007$ & $0.84(0.77-0.93)$ & Not selected \\
\hline 2008-2011 & $0.82(0.76-0.87)$ & \\
\hline $2012-2013$ & $0.94(0.87-1.00)$ & \\
\hline \multicolumn{3}{|l|}{ CD4 cell count (cells/mm³) (time-varying) } \\
\hline$<50$ & $2.29(2.25-2.32)$ & $2.27(2.24-2.31)$ \\
\hline 50-199 & $1.45(1.44-1.47)$ & $1.44(1.43-1.46)$ \\
\hline $200-349$ & $1.22(1.21-1.23)$ & $1.22(1.21-1.23)$ \\
\hline$\geq 350$ & $1(-)$ & $1(-)$ \\
\hline Unknown & $1.00(0.99-1.01)$ & $1.00(0.98-1.01)$ \\
\hline \multicolumn{3}{|l|}{ ART Adherence (time-varying) } \\
\hline$\geq 95 \%$ & $1(-)$ & $1(-)$ \\
\hline $80-94 \%$ & $1.19(1.17-1.20)$ & Not selected \\
\hline $40-79 \%$ & $1.20(1.19-1.22)$ & \\
\hline$<40 \%$ & $1.12(1.11-1.13)$ & \\
\hline \multicolumn{3}{|l|}{ Number of comorbidities (time-varying) } \\
\hline 0 & $1(-)$ & $1(-)$ \\
\hline 1 & $1.39(1.32-1.47)$ & $1.30(1.23-1.37)$ \\
\hline 2 & $1.87(1.76-1.99)$ & $1.64(1.54-1.75)$ \\
\hline$\geq 3$ & $2.82(2.67-2.99)$ & $2.34(2.21-2.48)$ \\
\hline \multicolumn{3}{|l|}{ Initial ART regimen } \\
\hline NNRTI & $1(-)$ & $1(-)$ \\
\hline bPI & $1.12(1.07-1.18)$ & Not selected \\
\hline Viral load (log $\log _{10}$ copies/mL) (time-varying) & $1.13(1.13-1.13)$ & Not selected \\
\hline
\end{tabular}

ART: combination antiretroviral therapy; NNRTI: non-nucleoside reverse transcriptase inhibitor; bPI: ritonavir-boosted protease inhibitor. Note that in the multivariable model we did not adjust for risk for HIV acquisition given its high collinearity with the main study exposure. Not selected means that the variable was not a confounder in the model

health systems perspective. Chronic $\mathrm{HCV}$ infection among PLW-HIV may have contributed to the exacerbation of progressive immunosenescence, and it may be associated with premature morbidity and mortality manifested by the development of multiple comorbidities (as observed in this study) [16, 53], further contributing to increased financial strain on healthcare systems.

The findings of the present study should be interpreted in light of several limitations. First, HIV/HCV co- 
infection status was assigned based on ever having recorded a positive $\mathrm{HCV}$ antibody test or detected $\mathrm{HCV}$ RNA. Thus, it is unknown whether these individuals had active HCV infection during the study period. Second, several factors such as rates of spontaneous viral clearance, HCV treatment and re-infection (among those successfully treated) were unknown for this cohort, thus limiting our ability to identify and adjust for these factors in the model. Third, therapy for opioid dependence was not considered, but may have impacted HRV among PLW-HIV/HCV with active injection drug use. Fourth, although healthcare administrative data are an important source of information for evidence-based clinical and policy decision-making as well as medical research, we should note that these data are susceptible to inaccurate or incomplete coding, potentially leading to missing or misclassified HRV in both groups. Finally, while this study examined HRV exclusively, there are other forms of healthcare utilization not accounted for in these analyses (e.g., addiction support services).

\section{Conclusions}

In conclusion, in this retrospective study, we found that although HRV rates have been decreasing steadily over time, PLW-HIV/HCV consistently maintained higher HVR rates relative to PLW-HIV. Our results highlight several modifiable risk factors (i.e., late presentation for ART, injection drug use, sub-optimal ART adherence and comorbidities) that could be targeted as potential means to minimize the disease burden of this population and on the healthcare system.

\section{Additional file}

Additional file 1: Supplementary information detailing the data linkage within the STOP HIV/AIDS cohort, the ascertainment of comorbidities based on the Charlson Comorbidity Index, and the number of healthcare-related visits recorded. (DOCX $35 \mathrm{~kb}$ )

\section{Abbreviations \\ ART: Combination antiretroviral therapy; BC: British Columbia; bPI: Ritonavir- boosted protease inhibitor; $\mathrm{Cl}$ : Confidence Interval; HCV: Hepatitis C virus; HRV: Healthcare-related visits; MSM: Men who have sex with men; MSP: Medical Services Plan; NNRTI: Non-nucleoside reverse transcriptase inhibitor; NRTI: Nucleoside/nucleotide reverse transcriptase inhibitor; PLW- HIV: People living with HIV/AIDS; PLW-HIV/HCV: People living with HIV and HCV; PWID: People who inject drugs; STOP HIV/AIDS: Seek and Treat for Optimal Prevention of HIV/AIDS}

\section{Acknowledgements}

We would like to thank our patients, and the physicians, nurses, social workers and volunteers who support them.

\section{Funding}

JSGM is supported with grants paid to his institution by the British Columbia Ministry of Health and by the US National Institutes of Health (R01DA036307). VDL is funded by a grant from the Canadian Institutes of Health Research (PJT148595), by a Scholar Award from the Michael Smith Foundation for Health Research and a New Investigator award from the Canadian Institutes of Health
Research. OE is supported by a Canadian Institutes of Health Research doctoral award. MH has received grant support from the National Institute on Drug Abuse (NIDA R01DA031043-01). The sponsors had no role in the design, data collection, data analysis, data interpretation, or writing of the report. The corresponding author had full access to all data in the study and had final responsibility to submit for publication.

\section{Availability of data and materials}

The authors confirm that, for approved reasons, some access restrictions apply to the data underlying the findings. All data is housed at the British Columbia Centre for Excellence in HIV/AIDS Drug Treatment Program. Given that we must protect the identity of Drug Treatment Program participants we cannot provide our study data to the public. We do not allow qualified researchers to obtain our data nor would it be possible to share anonymized data that underlie the summary statistics presented in this manuscript. If you have further questions regarding our data sharing and privacy policy please do not hesitate to contact our Director of Operations, Ms. Irene Day at iday@cfenet.ubc.ca.

\section{Authors' contributions}

The author's contributions were as follows: Initial study concept and design: VDL; Acquisition of data: VDL, BY, JSGM; Analysis and interpretation of data: HM, CFV, VDL, BY; Drafting of the manuscript: VDL, HM, MS; Consultation regarding study design and interpretation of findings: MS, OE, MRL, LT, MH, LW, RSH, RB, JAS, JSGM; Critical revision of the manuscript for important intellectual content: HM, CFV, MS, OE, MRL, LT, MH, BY, LW, RSH, RB, JAS, JSGM; Final approval of the manuscript to be published: HM, CFV, MS, OE, MRL, LT, MH, BY, LW, RSH, RB, JAS, JSGM; Statistical analysis: HM, CFV, VDL; Obtained funding: VDL, JSGM; Administrative, technical, or material support: VDL; Study supervision: VDL.

\section{Ethics approval and consent to participate}

Administrative database linkage and use was approved and performed by data stewards in each collaborating agency and facilitated by the BC Ministry of Health. The University of British Columbia Ethics Review Committee at the St. Paul's Hospital site provided ethics approval for this study (H08-02095). The study complies with BC's Freedom of Information and Protection of Privacy Act. As the study was conducted using anonymized administrative databases, informed consent was not obtained.

\section{Competing interests}

We have the following competing interests: JSGM has received limited unrestricted funding, paid to his institution, from Abbvie, Bristol-Myers Squibb, Gilead Sciences, Janssen, Merck, ViiV Healthcare. MH has received honoraria for speaking engagements and/or consultancy meetings from the following: Bristol Myers Squibb, Gilead, Merck, Ortho-Janssen, and ViiV. The remaining authors do not have conflicts to declare.

\section{Publisher's Note}

Springer Nature remains neutral with regard to jurisdictional claims in published maps and institutional affiliations.

\section{Author details \\ 'Department of Statistics, University of British Columbia, 3182 Earth Sciences Building, 2207 Main Mall, Vancouver, BC V6T 1Z4, Canada. ${ }^{2}$ British Columbia Centre for Excellence in HIV/AIDS, 608 - 1081 Burrard Street, Vancouver, BC V6Z 1Y6, Canada. ${ }^{3}$ Faculty of Health Sciences, Simon Fraser University, Blusson Hall, Room 10502, Burnaby, BC V5A 156, Canada. ${ }^{4}$ British Columbia Centre for Excellence in HIV/AIDS, 667 - 1081 Burrard Street, Vancouver, BC V6Z 1Y6, Canada. ${ }^{5}$ Department of Statistics, University of British Columbia, 3182 Earth Sciences Building room ESB 3126, 2207 Main Mall, Vancouver, BC V6T 1Z4, Canada. ${ }^{6}$ School of Population \& Public Health, University of British Columbia, 2206 East Mall, Rm 414, Vancouver, BC V6T 1Z3, Canada.}

Received: 9 June 2017 Accepted: 15 April 2018

Published online: 02 May 2018

\section{References}

1. Deeks SG, Lewin SR, Havlir DV. The end of AIDS: HIV infection as a chronic disease. Lancet. 2013;382(9903):1525-33. 
2. Lima VD, Lourenco L, Yip B, Hogg RS, Phillips P, Montaner JS. AIDS incidence and AIDS-related mortality in British Columbia, Canada, between 1981 and 2013: a retrospective study. Lancet HIV. 2015;2(3):e92-7.

3. Lima VD, Eyawo O, Ma H, Lourenco L, Chau W, Hogg RS, Montaner JS. The impact of scaling-up combination antiretroviral therapy on patterns of mortality among HIV-positive persons in British Columbia, Canada. J Int AIDS Soc. 2015;18:20261.

4. Deeks SG, Phillips AN. HIV infection, antiretroviral treatment, ageing, and non-AIDS related morbidity. BMJ. 2009;338:a3172.

5. Platt L, Easterbrook P, Gower E, McDonald B, Sabin K, McGowan C, Yanny I, Razavi H, Vickerman P. Prevalence and burden of HCV co-infection in people living with HIV: a global systematic review and meta-analysis. Lancet Infect Dis. 2016;16(7):797-808.

6. Ly KN, Hughes EM, Jiles RB, Holmberg SD. Rising mortality associated with hepatitis C virus in the United States, 2003-2013. Clin Infect Dis. 2016;62(10): 1287-8

7. Hepatitis C in Canada: 2005-2010 Surveillance Report [http://publications.gc. ca/site/eng/418441/publication.html].

8. HIV and Viral Hepatitis [https://www.cdc.gov/hiv/pdf/library/factsheets/hivviral-hepatitis.pdf].

9. Amin J, Kaye M, Skidmore S, Pillay D, Cooper DA, Dore GJ. HIV and hepatitis C coinfection within the CAESAR study. HIV Med. 2004;5(3):174-9.

10. Graham CS, Baden LR, Yu E, Mrus JM, Carnie J, Heeren T, Koziel MJ. Influence of human immunodeficiency virus infection on the course of hepatitis C virus infection: a meta-analysis. Clin Infect Dis. 2001;33(4):562-9.

11. Greub G, Ledergerber B, Battegay M, Grob P, Perrin L, Furrer H, Burgisser $P$ Erb P, Boggian K, Piffaretti JC, et al. Clinical progression, survival, and immune recovery during antiretroviral therapy in patients with HIV-1 and hepatitis C virus coinfection: the Swiss HIV cohort study. Lancet. 2000; 356(9244):1800-5.

12. Fernandez S, Price P, McKinnon EJ, Nolan RC, French MA. Low CD4+ T-cell counts in HIV patients receiving effective antiretroviral therapy are associated with CD4+ T-cell activation and senescence but not with lower effector memory T-cell function. Clin Immunol. 2006;120(2):163-70.

13. Deeks SG, Verdin E, McCune JM. Immunosenescence and HIV. Curr Opin Immunol. 2012;24(4):501-6.

14. Grady BP, Nanlohy NM, van Baarle D. HCV monoinfection and HIV/HCV coinfection enhance T-cell immune senescence in injecting drug users early during infection. Immun Ageing. 2016;13:10.

15. Gruener NH, Lechner F, Jung MC, Diepolder $H$, Gerlach $T$, Lauer G, Walker B, Sullivan J, Phillips R, Pape GR, et al. Sustained dysfunction of antiviral CD8(+) T lymphocytes after infection with hepatitis C virus. J Virol. 2001;75(12):5550-8.

16. Rallon N, Garcia M, Garcia-Samaniego J, Rodriguez N, Cabello A, Restrepo C, Alvarez B, Garcia R, Gorgolas M, Benito JM. HCV coinfection contributes to HIV pathogenesis by increasing immune exhaustion in CD8 T-cells. PLoS One. 2017;12(3):e0173943.

17. Cacoub P, Comarmond C, Domont F, Savey L, Desbois AC, Saadoun D. Extrahepatic manifestations of chronic hepatitis C virus infection. Ther Adv Infect Dis. 2016;3(1):3-14

18. Louie KS, St Laurent S, Forssen UM, Mundy LM, Pimenta JM. The high comorbidity burden of the hepatitis $C$ virus infected population in the United States. BMC Infect Dis. 2012;12:86.

19. Goulet JL, Fultz SL, Rimland D, Butt A, Gibert C, Rodriguez-Barradas M, Bryant K, Justice AC. Aging and infectious diseases: do patterns of comorbidity vary by HIV status, age, and HIV severity? Clin Infect Dis. 2007; 45(12):1593-601.

20. Janjua NZ, Islam N, Wong J, Yoshida EM, Ramji A, Samji H, Butt ZA, Chong $M$, Cook D, Alvarez $M$, et al. Shift in disparities in hepatitis $C$ treatment from interferon to DAA era: a population-based cohort study. J Viral Hepat. 2017; 24(8):624-30.

21. More patients to benefit from hepatitis $C$ treatments [https://news.gov.bc. $\mathrm{ca} / 13927]$

22. Patterson S, Cescon A, Samji H, Cui Z, Yip B, Lepik KJ, Moore D, Lima VD, Nosyk B, Harrigan PR, et al. Cohort profile: HAART observational medical evaluation and research (HOMER) cohort. Int J Epidemiol. 2015;44(1):58-67

23. British Columbia Centre for Excellence in HIV/AIDS: Therapeutic Guidlines Antiretroviral (ARV) Treatment of Adult HIV Infection In. http://www.cfenet. ubc.ca/sites/default/files/uploads/Guidelines/bccfe-art-guidelines-Oct_14_ 2015.pdf ; 2015.

24. Gunthard HF, Saag MS, Benson CA, del Rio C, Eron JJ, Gallant JE, Hoy JF, Mugavero MJ, Sax PE, Thompson MA, et al. Antiretroviral drugs for treatment and prevention of HIV infection in adults: 2016 recommendations of the international antiviral society-USA panel. JAMA. 2016;316(2):191-210.

25. HIV/AIDS Information System (HAISYS). Clinical Prevention Services, British Columbia Centre for Disease Control, 2016 [http://www.bccdc.ca/about/ accountability/data-access-requests/public-health-data].

26. Medical Services Plan (MSP) Payment Information File; Consolidation File (MSP Registration \& Premium Billing); Home \& Community Care (Continuing Care); Mental Health; PharmaNet. British Columbia Ministry of Health [publisher]. Data Extract. MOH (2016) [ http://www2.gov.bc.ca/gov/content/health/conductinghealth-research-evaluation/data-access-health-data-central].

27. Discharge Abstract Database (Hospital Separations). British Columbia Ministry of Health [publisher]. Data Extract. MOH (2016) [ http://www2.gov. bc.ca/gov/content/health/conducting-health-research-evaluation/dataaccess-health-data-central]

28. Vital Statistics. British Columbia Ministry of Health [publisher]. Data Extract. MOH (2016) [ http://www2.gov.bc.ca/gov/content/health/conductinghealth-research-evaluation/data-access-health-data-central].

29. Heath K, Samji H, Nosyk B, Colley G, Gilbert M, Hogg RS, Montaner JS, Group SHAS. Cohort profile: seek and treat for the optimal prevention of HIV/AIDS in British Columbia (STOP HIV/AIDS BC). Int J Epidemiol. 2014;43(4):1073-81.

30. HIV laboratory testing datasets (tests: ELISA, Western blot, NAAT, p24, culture). Clinical Prevention Services, British Columbia Centre for Disease Control, 2016 [http://www.bccdc.ca/about/accountability/data-accessrequests/public-health-data]

31. Cobb BR, Vaks JE, Do T, Vilchez RA. Evolution in the sensitivity of quantitative HIV-1 viral load tests. J Clin Virol. 2011;52(Suppl 1):S77-82.

32. Grebely J, Raffa JD, Lai C, Krajden M, Conway B, Tyndall MW. Factors associated with spontaneous clearance of hepatitis $C$ virus among illicit drug users. Can J Gastroenterol. 2007;21(7):447-51.

33. Population Estimates [http://www.bcstats.gov.bc.ca/StatisticsBySubject/ Demography/PopulationEstimates.aspx].

34. Lima VD, Bangsberg DR, Harrigan PR, Deeks SG, Yip B, Hogg RS, Montaner JS. Risk of viral failure declines with duration of suppression on highly active antiretroviral therapy irrespective of adherence level. J Acquir Immune Defic Syndr. 2010;55(4):460-5.

35. Quan H, Li B, Couris CM, Fushimi K, Graham P, Hider P, Januel JM, Sundararajan V. Updating and validating the Charlson comorbidity index and score for risk adjustment in hospital discharge abstracts using data from 6 countries. Am J Epidemiol. 2011;173(6):676-82.

36. Quan H, Sundararajan V, Halfon P, Fong A, Burnand B, Luthi JC, Saunders $L D$, Beck CA, Feasby TE, Ghali WA. Coding algorithms for defining comorbidities in ICD-9-CM and ICD-10 administrative data. Med Care. 2005; 43(11):1130-9.

37. McDonald JH. Handbook of biological statistics. Baltimore SHP: 2nd edition EDN; 2009.

38. Cameron AC, Trivedi PK. Regression analysis of count data. New York: Cambridge University Press; 1998.

39. Pinheiro JCB. D.M.: mixed-effects models in S and S-PLUS. New York: Springer-Verlag; 2000.

40. Maldonado G, Greenland S. Simulation study of confounder-selection strategies. Am J Epidemiol. 1993;138(11):923-36.

41. Lima VD, Geller J, Bangsberg DR, Patterson TL, Daniel M, Kerr T, Montaner J, Hogg RS. The effect of adherence on the association between depressive symptoms and mortality among HIV-infected individuals first initiating HAART. AIDS. 2007:21(9):1175-83.

42. Katrak S, Park LP, Woods C, Muir A, Hicks C, Naggie S. Patterns of healthcare utilization among veterans infected with hepatitis $C$ virus ( $\mathrm{HCV}$ ) and human immunodeficiency virus (HIV) and Coinfected with HIV/HCV: unique burdens of disease. Open Forum Infect Dis. 2016;3(3):ofw173.

43. Linas BP, Wang B, Smurzynski M, Losina E, Bosch RJ, Schackman BR, Rong J, Sax PE, Walensky RP, Schouten J, et al. The impact of HIV/HCV co-infection on health care utilization and disability: results of the ACTG Iongitudinal linked randomized trials (ALLRT) cohort. J Viral Hepat. 2011;18(7):506-12.

44. Crowell TA, Berry SA, Fleishman JA, LaRue RW, Korthuis PT, Nijhawan AE, Moore RD, Gebo KA, Network HIVR. Impact of hepatitis coinfection on healthcare utilization among persons living with HIV. J Acquir Immune Defic Syndr. 2015;68(4):425-31.

45. Olding M, Enns B, Panagiotoglou D, Shoveller J, Harrigan PR, Barrios R, Kerr T, Montaner JSG, Nosyk B. A historical review of HIV prevention and care initiatives in British Columbia, Canada: 1996-2015. J Int AIDS Soc. 2017:20(1):21941. 
46. Theapeutic Guidelines for Antiretroviral Treatment (ARV) of Adult HIV Infection [http://www.cfenet.ubc.ca/sites/default/files/uploads/ BCCfE\%20Adult\%20Therapeutic\%20Guidelines_Jan2011.pdf].

47. Lima VD, Rozada I, Grebely J, Hull M, Lourenco L, Nosyk B, Krajden M, Yoshida E, Wood E, Montaner JS. Are interferon-free direct-acting antivirals for the treatment of HCV enough to control the epidemic among people who inject drugs? PLoS One. 2015;10(12):e0143836.

48. Smyth $D$, Webster $D$. Hepatitis $C$ virus infection: accessing drug treatment. CMAJ. 2015;187(15):1113-4

49. Islam N, Krajden M, Shoveller J, Gustafson P, Gilbert M, Buxton JA, Wong J, Tyndall M, Janjua NZ. Incidence, risk factors, and prevention of hepatitis C reinfection: a population-based cohort study. The Lancet Gastroenterology \& Hepatology. 2017;2(3):200-10

50. Hepatitis C Research Program [http://www.cfenet.ubc.ca/research/hepatitisc-research-program]

51. British Columbia Centre on Substance Use [http://www.cfenet.ubc.ca/ research/bccsu/about]

52. Aging with HIV: Long, healthy lives are possible with treatment [http://news.ubc. ca/2015/11/30/aging-with-hiv-long-healthy-lives-are-possible-with-treatment/].

53. Operskalski EA, Kovacs A. HIV/HCV co-infection: pathogenesis, clinical complications, treatment, and new therapeutic technologies. Curr HIV/AIDS Rep. 2011:8(1):12-22

Ready to submit your research? Choose BMC and benefit from:

- fast, convenient online submission

- thorough peer review by experienced researchers in your field

- rapid publication on acceptance

- support for research data, including large and complex data types

- gold Open Access which fosters wider collaboration and increased citations

- maximum visibility for your research: over $100 \mathrm{M}$ website views per year

At BMC, research is always in progress.

Learn more biomedcentral.com/submissions 